\title{
Adsorption of Strontium onto Adaxial and Abaxial Cuticle of Photinia serrulata Leaf
}

\author{
Yungui Li ${ }^{1,2, * \mathbb{D}}$, Xiang Luo ${ }^{1,2}$, Xueying Bai ${ }^{1,2}$, Wenxuan Lv ${ }^{1,2}$ and Yang Liao ${ }^{1,2}$ \\ 1 Department of Environmental Engineering, Southwest University of Science and Technology, \\ Mianyang 621010, China; lx_luoxiang@163.com (X.L.); 15036027220@163.com (X.B.); \\ wenxuan2807940648@163.com (W.L.); liaoyangswust@yeah.net (Y.L.) \\ 2 Sichuan Provincial Sci-Tech Cooperation Base of Low-cost Wastewater Treatment Technology, Southwest \\ University of Science and Technology, Mianyang 621010, China \\ * Correspondence: liyungui@swust.edu.cn
}

Received: 12 December 2019; Accepted: 29 January 2020; Published: 7 February 2020

\begin{abstract}
Leaf cuticle sorption is one important process for the uptake of environment pollutants in plants, and mixed powder including adaxial and abaxial cuticle is generally used to demonstrate the sorption behavior. However, the difference of adaxial and abaxial cuticle on plant cuticle sorption is not well understood. Abaxial cuticle (PAC) and adaxial cuticle (PBC) were isolated from hypostomatic Photinia serrulata to investigate their adsorption of a model radionuclide (strontium). The elemental composition and FTIR spectra for two cuticles were quite similar and both show high affinity $(\mathrm{H} / \mathrm{C}$, 1.59 and 1.65) and polarity $((\mathrm{O}+\mathrm{N}) / \mathrm{C}, 0.470$ and 0.499$)$. Both adsorption isotherms fit well with Langmuir model $\left(R^{2}, 0.97\right.$ and 0.97$)$, and the maximum adsorption capacity of PAC was $12.1 \mathrm{mg} / \mathrm{g}$, little higher than that of PBC $(10.3 \mathrm{mg} / \mathrm{g})$. Adsorption of strontium increased with the increase of $\mathrm{pH}$, and the maximum was attained when $\mathrm{pH} \geq 4$. Electrostatic attraction was demonstrated to be the main mechanism of -strontium adsorption onto PAC and PBC, and the similar adsorption of adaxial and abaxial cuticle was consistent with their similar isoelectric point.
\end{abstract}

Keywords: leaf cuticle; strontium; adsorption; adaxial; abaxial

\section{Introduction}

With the rapid development of global industrialization, especially the exacerbation of the energy crisis, nuclear energy has undergone dramatic progress. Up to now, more than 400 nuclear power plants have been put into operation, and the consequent threats to the environment have raised widespread concerns, as the three major nuclear disasters occurred in Three Mile Island, Chernobyl, and Fukushima brought about severe damage to human health and ecological safety [1-3]. Plants adsorption, primarily via root and foliar uptakes, is not only the beginning of the transmission of nuclides in the food chain, but also an important route of human and animal exposure to radionuclides [4-6]. Madoz-Escande et al. [7] found that, within one year after nuclear leak, the nuclides in the bodies of plants were mostly absorbed via foliar uptake rather root uptake. For some radionuclides (e.g., ${ }^{131} \mathrm{I}$ and ${ }^{125} \mathrm{I}$ ), the non-root uptake is a primary and even the only channel to enter the plants. One month after the nuclear meltdown in Fukushima, the absorbed radiation level in plants $35 \mathrm{~km}$ away was 10 times higher than that in the soil. As a primary means of long-range migration of pollutants into the plants, foliar uptake is also crucial to the "sink" mechanism of pollutants and the safety of agricultural products [8-10].

Leaf cuticle, the film-like structure composed of wax, cutin, cutan and polysaccharide, is the first barrier that contacts with and absorbs nuclides, as well as a vital carrier of environmental pollutants accumulation [11-13]. Through investigation on the nuclear leak at Fukushima Plant, Nishikiori et al. [10] found that $60 \%-80 \%$ of ${ }^{137}$ Cs on the leaves of cedar were adhered on the epidermis, while $20 \%-40 \%$ existed inside the leaves and could be transferred from the old leaves to new ones. 
Cuticle adsorption is a fundamental process of foliar uptake and accumulation, and the adsorption rate and capacity will greatly impact on the uptake and accumulation of contaminants. So far, the existing research on cuticle adsorption have mostly focused on organic contaminants $[11,14,15]$, while the cuticle adsorption of nuclides is rarely reported, and its mechanism remains unclear.

At present, studies on cuticle adsorption mainly investigated the mixed cuticle, i.e., with the adaxial and abaxial foliar cuticles unseparated [11-13]. However, there remain some differences in structure between the adaxial and abaxial foliar cuticles of most plants, especially angiosperms, the stomas of which are typically located in the abaxial epidermis [9]. The adaxial and abaxial cuticular topographies are distinct from each other resulting in different pollutant uptake behaviors [16,17]. Stomata located in abaxial cuticle was suggested to contribute importantly in the uptake of chemicals by plants, as the pore structures would offer a rapid access of toxicants to the deeper cuticle parts [18]. However, Li et al. [9] found that the highest intensity of phenanthrene in the adaxial cuticle was nearly twice as much as that in the abaxial cuticle. The impact of this structural difference on the nuclide adsorption is still unknown. In addition, the probabilities for the abaxial and adaxial foliar cuticles to be exposed to contaminants are importantly different, as the probability for the adaxial ones is much higher than the abaxial ones. If so, the referential significance of the results from studies on the mixed cuticles requires further investigation. For this reason, the focus of this study was aimed at the differences in the composition and adsorption behavior between the adaxial and abaxial cuticles. The common dicotyledonous Photinia fraseri was selected as the subject leaves, and the composition differences between the abaxial and adaxial foliar cuticles were analyzed through elemental analysis, and Fourier transform infrared spectroscopy (FTIR). Taking the most extensively studied strontium as the representative nuclide [19], a batch adsorption was adopted to explore the adsorption characteristics of the abaxial and adaxial cuticles in an attempt to provide a theoretical basis for the accurate prediction of the nuclide activities in foliar uptake.

\section{Material and Methods}

\subsection{Samples Collection}

Mature leaves of Photinia serrulata (Figure 1) were collected on the campus of Southwest University of Science and Technology, China, and washed with distilled water to remove the dust from the surface. Cuticles were detached using the method described in an earlier report [9]. Then the air dried leaves were weighed and vertically cut in the main vein (in order to facilitate separation), put into the mixture of $30 \% \mathrm{H}_{2} \mathrm{O}_{2}$ and glacial acetic acid at 1:1, and heated by a $60^{\circ} \mathrm{C}$ water bath until the leaves faded into transparent (about $10 \mathrm{~h}$ ). The abaxial and adaxial foliar cuticles were carefully peeled off by thin-tipped tweezers while being kept as intact as possible (Figure 1). The separated cuticles were stirred by using a magnetic stirrer to sufficiently remove the margins and mesophyll tissues, rinsed with distilled water again, heated at $60^{\circ} \mathrm{C}$, ground, sieved through a 100-mesh sieve, and kept separately as samples.
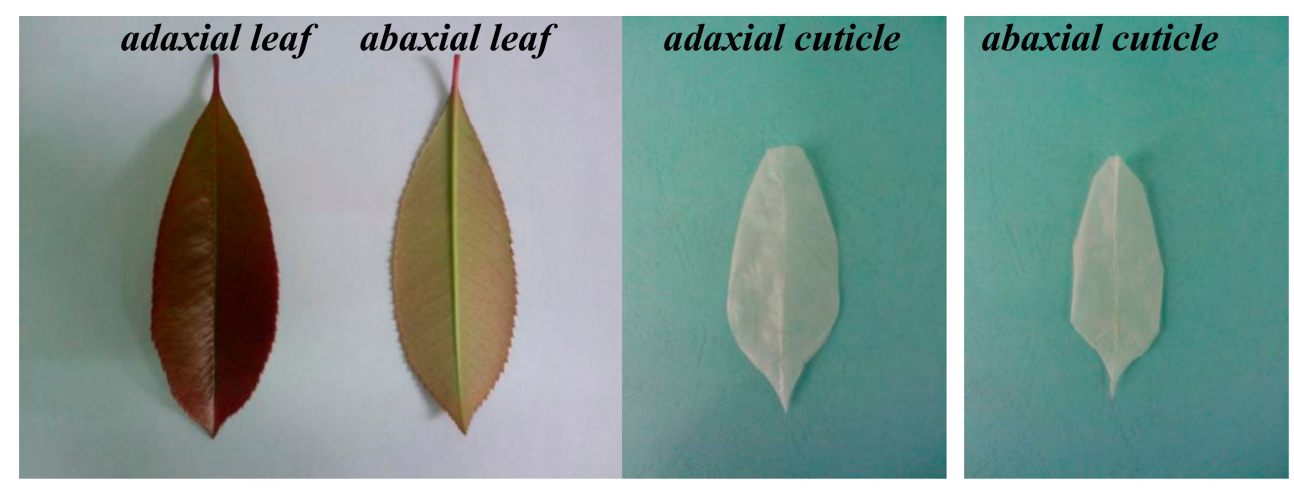

Figure 1. Graph of selected adaxial (PAC) and abaxial (PBC) cuticle as well as adaxial and abaxial Photinia serrulata Leaf. 


\subsection{The Characterization of Abaxial and Adaxial Cuticles}

The leaves of Photinia fraseri were placed on the sample compartment containing conductive paste, and the surface morphology of abaxial and adaxial foliar cuticles were observed via a scanning electron microscope (Leica S440). The CHN elemental analyzer (Vario EL CUBE, Germany) was employed to determine the element contents of $\mathrm{C}, \mathrm{H}$, and $\mathrm{N}$ in the abaxial and adaxial cuticles, while the oxygen content was calculated by the mass difference. The $\mathrm{H} / \mathrm{C}$ and $(\mathrm{O}+\mathrm{N}) / \mathrm{C}$ atomic ratios were calculated to evaluate the aliphatic nature and polarity of the selected cuticles. FTIR spectra were recorded in the $4000 \mathrm{~cm}^{-1}-400 \mathrm{~cm}^{-1}$ region for a KBr-pellet by a Nicolet FTIR spectrophotometer (Nicolet 5700) with a resolution of $2 \mathrm{~cm}^{-1}$.

\subsection{Batch Adsorption Experiment}

Strontium was chosen as a representative nuclide, and the salt of $\mathrm{SrCl}_{2} \cdot 6 \mathrm{H}_{2} \mathrm{O}$ was used to prepare the stock solution of Sr. The adsorption of adaxial and abaxial cuticles was performed with the specific solid (50 mg) to-solution $(8 \mathrm{~mL}$ ) ratios adjusted to achieve $30 \%-80 \%$ removal rate of sorbate at apparent equilibrium in comparison with initial concentration. Each adsorption isotherm consisted of ten concentration points ranging from 1.5 to $100 \mathrm{mg} \cdot \mathrm{L}^{-1}$ while each point included the control and calibration. The vials were full-filled with sorbate solution to minimize the headspace volumes of vials, sealed with Teflon screw caps to avoid sorbate's evaporation, and then agitated in the dark for $1 \mathrm{~h}$ (kinetic experiment indicating adsorption obtained equilibrium with $30 \mathrm{~min}$ ) at $25 \pm 0.5^{\circ} \mathrm{C}$ in the dark at an agitating rate of $150 \mathrm{r} \cdot \mathrm{min}^{-1}$. After agitation, the solution was filtered by a $0.45-\mu \mathrm{m}$ aqueous phase needle filters and measured by a Perkin-Elmer Analyst 700 (PE700, Waltham, MA, USA) atomic adsorption spectrometer with a wavelength of $460.7 \mathrm{~nm}$. The residual solid (cuticle with and without Sr) was dried for FTIR analysis. Because of the minimal sorption by the vials, and negligible losses from evaporation and degradation (considering the limited equilibrium time), the sorbed amount was then determined by difference in aqueous concentration between nominal aqueous concentration without sorbent and with sorbent.

Surface charge properties of adaxial and abaxial cuticles were measured with zeta potential. Cuticle $\left(2.5 \mathrm{~g} \cdot \mathrm{L}^{-1}\right)$ was suspended in deionized water or $20 \mathrm{mg} \cdot \mathrm{L}^{-1}$ Sr solution and adjusted to $\mathrm{pH} 1-7$, and the zeta potential was obtained by a Zetasizer (Nano ZS90, Malvern, UK). The $\mathrm{pH}$ of the cuticle suspension was adjusted using $1 \mathrm{~mol} \cdot \mathrm{L}^{-1} \mathrm{HCl}$ or $1 \mathrm{~mol} \cdot \mathrm{L}^{-1} \mathrm{NaOH}$. At the same time, the final values of $\mathrm{pH}$, and removal rate of sorbate were measured for the solutions before and after adsorption.

\subsection{Data Analysis}

The amount of $S r$ adsorbed onto the cuticles $\left(Q_{e}\right)$ was calculated by mass equilibrium (Equation (1)), and removal rate $(R)$ of $\mathrm{Sr}$ was calculated according to Equation (2).

$$
\begin{aligned}
Q_{\mathrm{e}} & =\frac{\left(C_{0}-C_{e}\right) \times V}{1000 \times m} \\
R \% & =\frac{\left(C_{0}-C_{e}\right) \times 100}{C_{0}}
\end{aligned}
$$

where $Q_{e}$ is the amount sorbed per unit weight of sorbent $\left(\mathrm{mg} \cdot \mathrm{g}^{-1}\right), C_{0}$ and $C_{\mathrm{e}}$ are the original and equilibrium $\mathrm{Sr}$ concentration in aqueous phase $\left(\mathrm{mg} \cdot \mathrm{L}^{-1}\right)$, respectively, $V$ is the solution volume $(\mathrm{mL})$, and $m$ is the cuticle mass (mg).

Both Langmuir (Equation (3)) and Freundlich (Equation (4)) models were used to describe the sorption isotherm of cuticles.

$$
\text { Langmuir model } \frac{C_{e}}{Q_{e}}=\frac{1}{K_{L} \times Q_{m}}+\frac{C_{e}}{Q_{m}}
$$




$$
\text { Freundlich model } Q_{\mathrm{e}}=K_{f} \times C_{e}^{N}
$$

where $Q_{\mathrm{e}}$ is the amount sorbed per unit weight of sorbent $\left(\mathrm{mg} \cdot \mathrm{g}^{-1}\right) ; C_{\mathrm{e}}$ is the equilibrium concentration $\left(\mathrm{mg} \cdot \mathrm{L}^{-1}\right)$; Langmuir $Q_{\mathrm{m}}\left(\mathrm{mg} \cdot \mathrm{g}^{-1}\right)$ is the maximum sorption amount per unit weight of sorbent, and $K_{\mathrm{L}}$ indicates the affinity between adsorbent and adsorbate, as the greater the $K_{\mathrm{L}}$, the greater the affinity; $K_{\mathrm{f}}\left[(\mathrm{mg} / \mathrm{g}) /(\mathrm{mg} / \mathrm{L})^{N}\right]$ is the Freundlich capacity coefficient, and $N$ (dimensionless) describes the isotherm curvature.

\section{Results and Discussion}

\subsection{The Characterizations of Cuticles}

SEM was applied to observe the surface morphology of the abaxial and adaxial cuticles (Figure 2). The adaxial cuticle was slightly wrinkled with bumps of waxy crystal, while protruding stomata was irregularly spread of on the surface of abaxial cuticle. The stomas were approximately $16 \mu \mathrm{m}$ in diameter and $3.5 \mu \mathrm{m}$ in opening length with a density of about $70,000 / \mathrm{cm}^{2}$, and the stoma area accounted for nearly $10 \%$ of the area of the adaxial foliar cuticle.
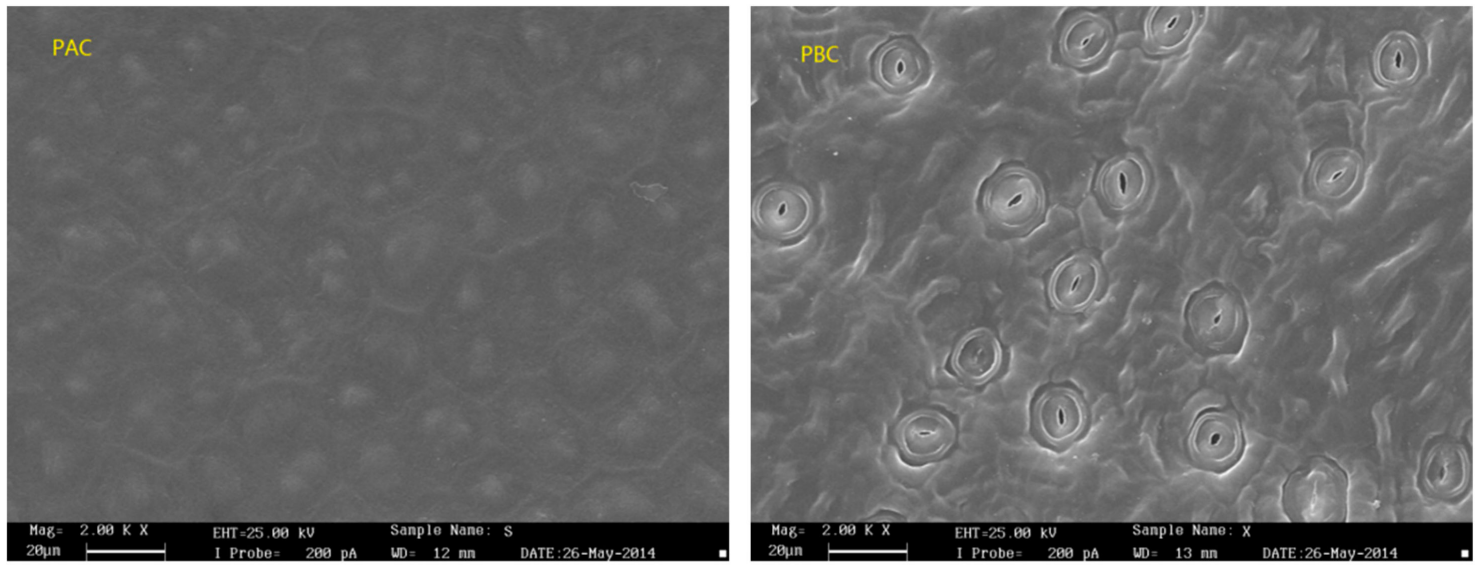

Figure 2. SEM micrographs of adaxial (PAC) and abaxial (PBC) cuticle of Photinia serrulata Leaf.

The yield and chemical properties of the adaxial and abaxial leaf cuticles are shown in Table 1. For one piece of fresh leaf, the amount of adaxial cuticle (7.01\%) was a little higher than that of abaxial one $(5.78 \%)$. The elemental compositions of both cuticles were very similar, with high level of organic carbon $(56.88 \%$ and $55.60 \%$, respectively). $\mathrm{H} / \mathrm{C}$ ratio characterized the extent of aromaticity of the samples, while the $(\mathrm{O}+\mathrm{N}) / \mathrm{C}$ ratio characterized the extent of polarity. The $\mathrm{H} / \mathrm{C}$ atomic ratios were respectively 1.59 and 1.65, suggesting that both the abaxial and adaxial leaf cuticles were highly fatty. The $(\mathrm{O}+\mathrm{N}) / \mathrm{C}$ atomic ratios were respectively 0.47 and 0.50 , suggesting high polarities of leaf cuticles [9].

Table 1. Yields and elemental analysis of adaxial (PAC) and abaxial (PBC) cuticle of Photinia serrulata Leaf.

\begin{tabular}{cccccccc}
\hline Sample & ${\text { Yield } / \%^{a}}^{a}$ & $\mathbf{C} / \%$ & $\mathbf{H} / \%$ & $\mathbf{N} / \%$ & $\mathbf{O} / \%^{\boldsymbol{b}}$ & H/C & $(\mathbf{O}+\mathbf{N}) / \mathbf{C}$ \\
\hline adaxial cuticle & 7.01 & 56.88 & 7.55 & 0.45 & 35.12 & 1.59 & 0.47 \\
abaxial cuticle & 5.78 & 55.60 & 7.63 & 0.45 & 36.32 & 1.65 & 0.50 \\
\hline
\end{tabular}

Notes: a Yield of cuticles was calculated to the percentage contents of correspondingly fresh weight of leaves. b Oxygen content was calculated by the mass difference.

The FTIR spectra of abaxial and adaxial leaf cuticles are shown in Figure 3. The adsorption peaks nearby 2926, 2855, and $1431 \mathrm{~cm}^{-1}$ were assigned mainly to $\mathrm{CH}_{2}$ units of aliphatic components of the cuticle, including wax, cutin and cutan. The bands at 1736 and $1164 \mathrm{~cm}^{-1}$ were the carboxyl $\mathrm{C}=\mathrm{O}$ and C-O stretching vibration peaks of cutin, respectively. The peaks at $1629 \mathrm{~cm}^{-1}$ was assigned to aromatic 
ring $\mathrm{C}=\mathrm{C}, \mathrm{C}=\mathrm{O}$, mainly derived from polymeric cutan. The bands at $1048 \mathrm{~cm}^{-1}\left(1056 \mathrm{~cm}^{-1}\right)$ and the surrounding shoulder peaks were assigned to $\mathrm{C}-\mathrm{O}-\mathrm{C}$ and $\mathrm{OH}$, mainly from the polysaccharide components of the cuticle. Generally, the functional group distribution of the adaxial and abaxial cuticles was quite similar in the current study, and distinctively different from the result of $\mathrm{Li}$ et al. [9] in that the band intensity of adaxial cuticle was much stronger than abaxial ones (intact cuticle). This was mainly attributed to the different sample shape (cuticle powder in current study while intact cuticle in the related reference).

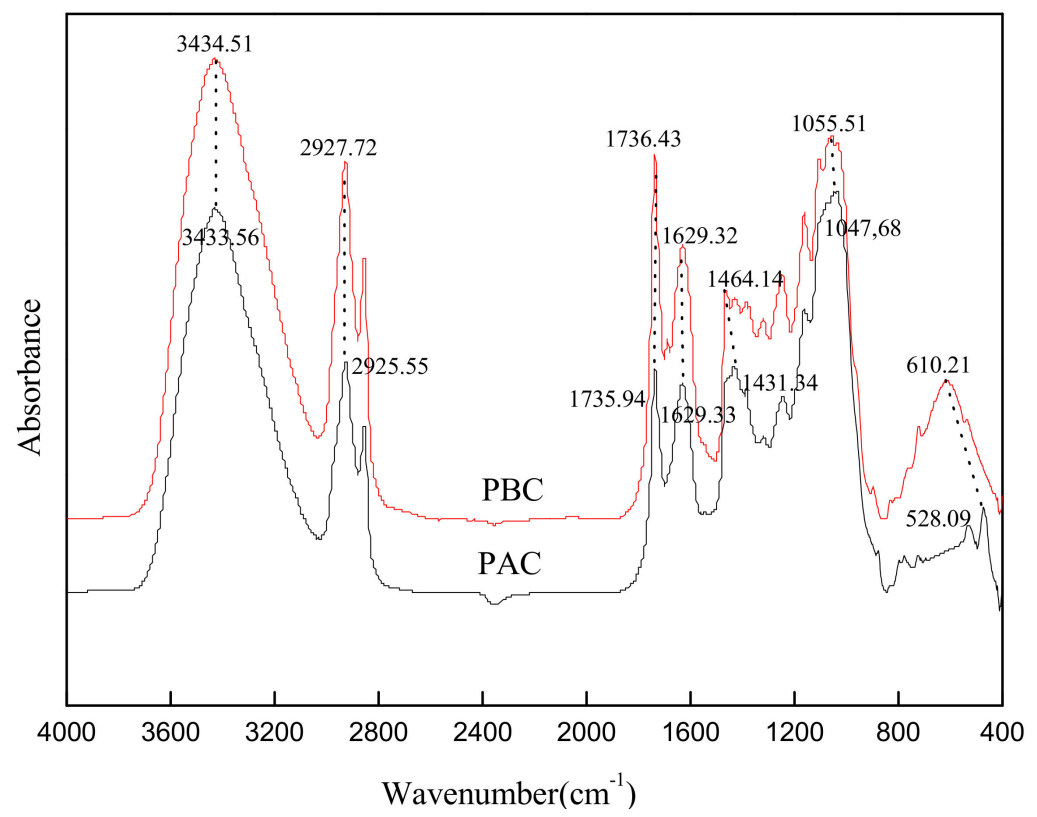

Figure 3. FTIR spectra of adaxial (PAC) and abaxial (PBC) cuticle of Photinia serrulata Leaf.

\subsection{Adsorption Kinetics}

The adsorption kinetics of the adaxial and abaxial foliar cuticles of Photinia fraseri for Sr are shown in Figure 4. The adsorption process is a dynamic equilibrium process of adsorption-desorption. The adsorption rate mostly depends on the physicochemical structure of the sample and the nuclide ions characteristics. Adsorption of $\mathrm{Sr}$ on the leaf cuticle of Photinia fraseri is up to the adsorption equilibrium within $10 \mathrm{~min}$, and the adsorption rate is faster than that of the moss adsorption of $\mathrm{Sr}$ [20], but a little lower than almond peel hell [19]. The rapid adsorption of radionuclides in the cuticle has an important effect on the migration and transformation of radionuclides in the environment. On one hand, the rapid adsorption of nuclides onto a cuticle can reduce the environmental mobility of radionuclides, reducing the pollution range of nuclides and decreasing the exposure to nuclides in soil and water environment. In contrast, fast-adsorbed nuclides can be absorbed by plants, and then enter the food chain endangering human health and ecological safety.

\subsection{Adsorption Isotherm}

The adsorption isotherms of the adaxial and abaxial foliar cuticles of Photinia fraseri for Sr are shown in Figure 5. The adsorption characteristics of the abaxial and adaxial foliar cuticles were very similar, but represented a significant departure with respect to organic pollutants [9]. With an increase in the initial concentration of $\mathrm{Sr}$, the adsorption amounts onto the abaxial and adaxial foliar cuticles showed an obvious upward trend, while the removal rate firstly increased and then decreased. This is because when the concentrations were relatively low, the collision probability of sorbates and cuticle is small, leading to low removal rate. With increasing of the concentration of $\mathrm{Sr}$ in aqueous solution up to $\leq 1 \mathrm{mg} \cdot \mathrm{L}^{-1}$, the accessibility of the cuticles sorbing sites by Sr increased significantly resulting in a growing trend in the adsorption rate. However, considering the limited adsorption sites, there 
was a gradual downward trend of the adsorption rate with a further increase in the concentration of nuclide ions $\left(\geq 1 \mathrm{mg} \cdot \mathrm{L}^{-1}\right)$.

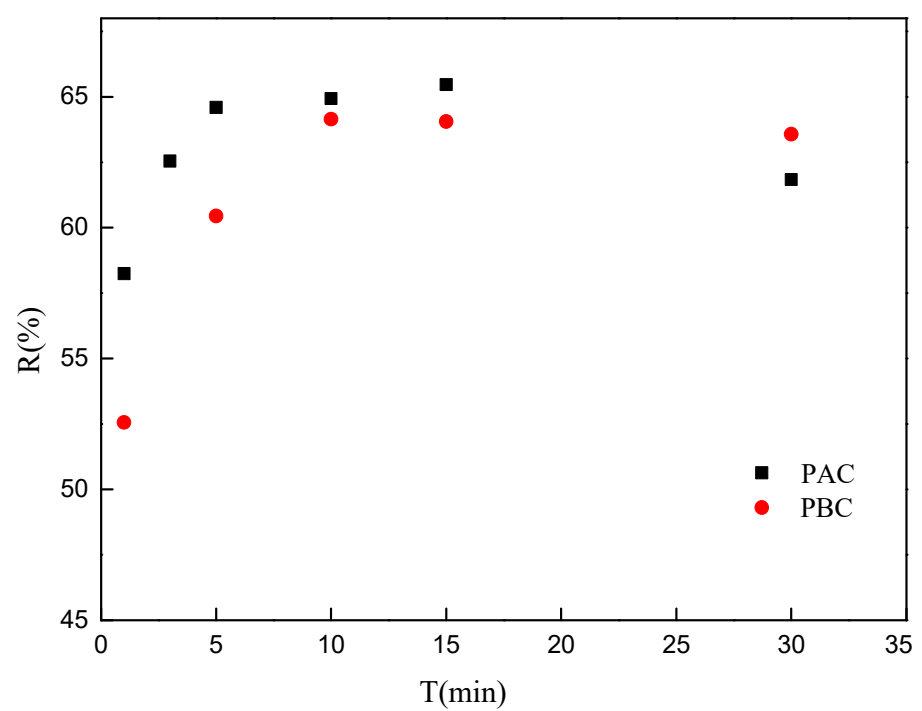

Figure 4. Adsorption kinetic of Sr by adaxial (PAC) and abaxial (PBC) cuticle of Photinia serrulata Leaf.

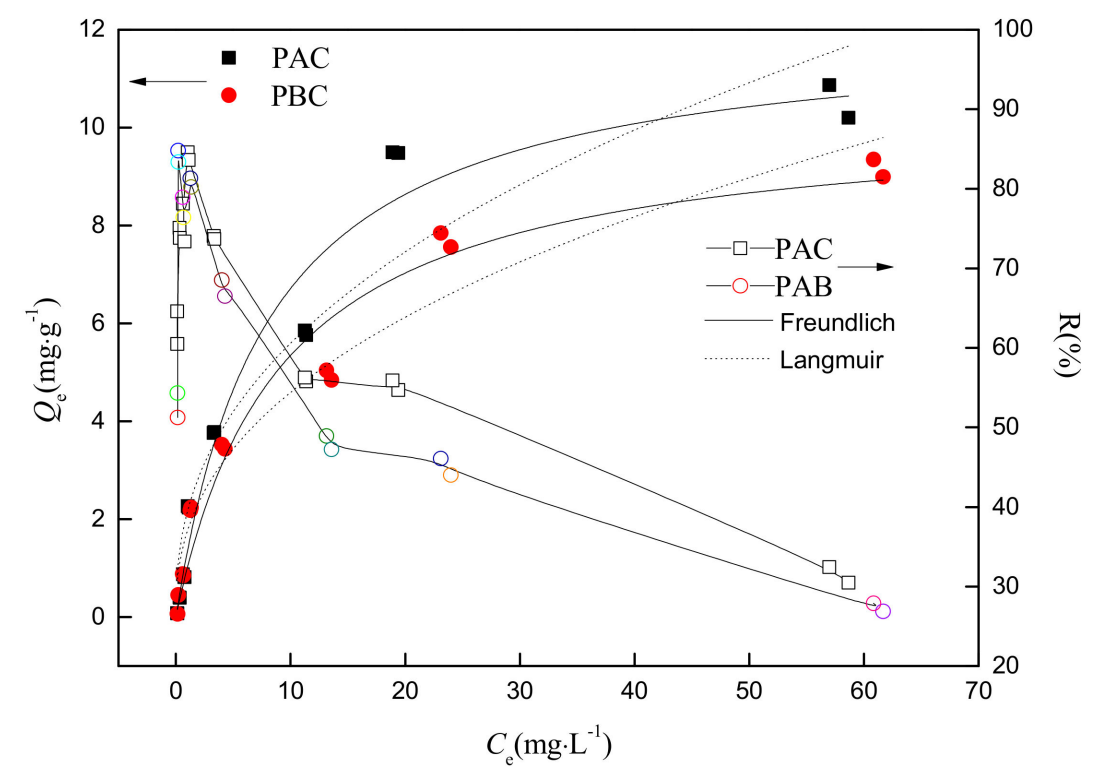

Figure 5. The adsorption isotherm and the adsorption percentage of Sr by adaxial (PAC) and abaxial (PBC) cuticles of Photinia serrulat Leaf. The solid and open legends represent the mass of adsorbed $\mathrm{Sr}$ $\left(Q_{\mathrm{e}}\right)$ and adsorption percentage of $\mathrm{Sr}(R \%)$ in an equilibrated system.

The regression parameters of Langmuir and Freundlich models of the adsorption isotherm are shown in Table 2. Compared with the Freundlich model ( $R^{2}$ were 0.92 and 0.96 , respectively), the Langmuir model ( $R^{2}$ were 0.97 and 0.97 , respectively) could more accurately describe the adsorption process of Photinia fraseri cuticle for Sr. $K_{\mathrm{L}}$ (PAC) $(0.125)$ and $K_{\mathrm{L} \text { (PBC) }}(0.109)$ were very close, suggesting that the affinity between adaxial and abaxial cuticle and $\mathrm{Sr}$ was quite similar. The theoretical maximum adsorption capacity of adaxial cuticle $\left(12.1 \mathrm{mg} \cdot \mathrm{g}^{-1}\right)$ was slightly higher than that of abaxial cuticle $\left(10.3 \mathrm{mg} \cdot \mathrm{g}^{-1}\right)$, which was similar to the maximum adsorption capacities obtained in experiments (adaxial cuticle, $10.8 \mathrm{mg} \cdot \mathrm{g}^{-1}$; abaxial cuticle, $\left.9.3 \mathrm{mg} \cdot \mathrm{g}^{-1}\right)$. These results were also close to the sorption capacity of moss (14.0 $\left.\mathrm{mg} \cdot \mathrm{g}^{-1},[20]\right)$, root tissues $\left(12.89 \mathrm{mg} \cdot \mathrm{g}^{-1}\right.$, [21]) and Sunflower straw (17.48 $\mathrm{mg} \cdot \mathrm{g}^{-1}$, [22]). The similar adsorption capacity of cuticle and plant tissue in references indicated that both adaxial and 
abaxial cuticles don't play a negative role on the absorption of nuclides which was usually considered to be a barrier for the foliar uptake of pollutants.

Table 2. Regression parameters of Langmuir and Freundlich model for the sorption of Strontium by adaxial (PAC) and abaxial (PBC) cuticle of Photinia serrulata Leaf.

\begin{tabular}{ccccccc}
\hline \multirow{2}{*}{ Sample } & \multicolumn{3}{c}{ Langmuir Regression Parameters } & \multicolumn{2}{c}{ Freundlich Regression Parameters } \\
\cline { 2 - 7 } & $\boldsymbol{K}_{\mathbf{L}} /\left(\mathbf{L} \cdot \mathbf{m g}^{\mathbf{- 1}}\right)$ & $Q_{\max } /\left(\mathbf{m g} \cdot \mathbf{g}^{\mathbf{- 1}}\right)$ & $\boldsymbol{R}^{\mathbf{2}}$ & $\boldsymbol{K}_{\mathbf{f}} /(\mathbf{m g} / \mathbf{g}) /(\mathbf{m g} / \mathbf{L})^{\mathbf{N}}$ & $\boldsymbol{N}^{\mathbf{2}}$ & $\boldsymbol{R}^{\mathbf{2}}$ \\
\hline PAC & $0.125 \pm 0.023$ & $12.1 \pm 0.71$ & 0.97 & $2.15 \pm 0.32$ & $0.415 \pm 0.044$ & 0.92 \\
PBC & $0.109 \pm 0.021$ & $10.3 \pm 0.64$ & 0.97 & $1.76 \pm 0.20$ & $0.417 \pm 0.032$ & 0.96 \\
\hline
\end{tabular}

Notes: $Q_{\mathrm{e}}$ is the amount sorbed per unit weight of sorbent, $\mathrm{mg} \cdot \mathrm{g}^{-1} ; C_{\mathrm{e}}$ is the equilibrium concentration, $\mathrm{mg} \cdot \mathrm{L}^{-1}$;

$K_{f}\left[(\mathrm{mg} / \mathrm{g}) /(\mathrm{mg} / \mathrm{L})^{\mathrm{N}}\right]$ is the Freundlich capacity coefficient; and $N$ (dimensionless) describes the isotherm curvature. $R^{2}$ is regression coefficient.

The specific activity of the radionuclide ${ }^{90} \mathrm{Sr}$ which was corresponding to the saturated adsorption capacity was $5.7 \times 10^{13} \mathrm{~Bq} \cdot \mathrm{kg}^{-1}$ (adaxial cuticle) and $4.9 \times 10^{13} \mathrm{~Bq} \cdot \mathrm{kg}^{-1}$ (abaxial cuticle), classified as high-level radioactive waste. Therefore, the cuticles had a strong retention capacity for the nuclides in the environment, while its high radioactivity is a great safety risk.

\subsection{Effect of $\mathrm{pH}$ on Sr Adsorption}

The effect of $\mathrm{pH}$ on the adsorption behavior of adaxial and abaxial cuticles is shown in Figure 6, and the initial and final $\mathrm{pH}$ values of adsorption working solution are also shown in Figure 7. Considering the significance of surface charge properties on metal ion sorption behavior [23], the corresponding zeta potential of cuticle particles with and without $\mathrm{Sr}$ loading was also determined (Figure 6). Ionization and protonation of the functional group (such as $-\mathrm{O}-,-\mathrm{OH},=\mathrm{O},-\mathrm{COOH},-\mathrm{NH}_{2}$ ) of cuticle particles surface directly changes upon interaction with $\mathrm{H}^{+}$or $\mathrm{OH}^{-}$with the various $\mathrm{pH}$ values, resulting different zeta potential [24].

The surface charge characteristics of the abaxial and adaxial foliar cuticles were very similar (Figure 6), and the isoelectric points were around 2.0 before and after the loading of Sr. When the solution $\mathrm{pH}$ values were greater than the isoelectric point, the zeta potential of particles changed to a negative value, indicating that the cuticles carried a negative charge. Since Sr carried a positive charge, the two could be bound together by electrostatic attraction. The low isoelectric point of the Photinia fraseri cuticle provided a strong adsorption capacity for the cations of nuclides within a large range of $\mathrm{pH}$. The value of the isoelectric point was closely related to the adsorption and accumulation of nuclide ions in the cuticles, and was an important indicator for phytoremediation of nuclide contamination and prevention of agricultural contamination.
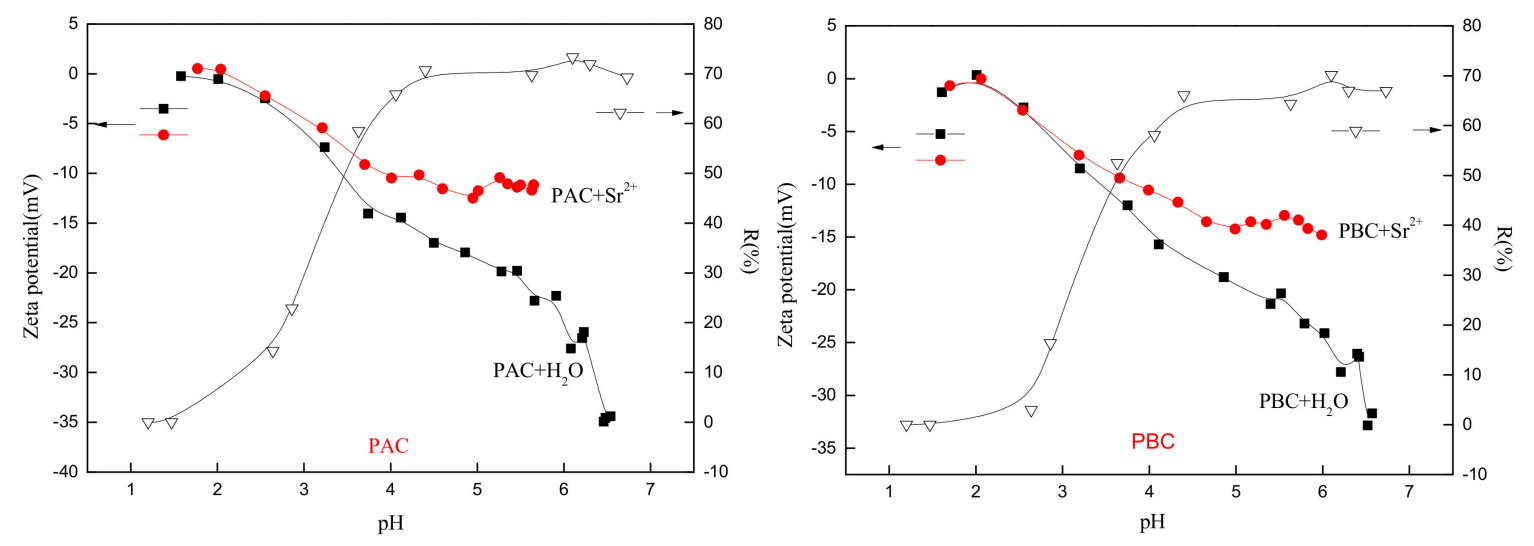

Figure 6. Effect of $\mathrm{pH}$ on Sr adsorption and zeta potential of adaxial (PAC) and abaxial (PBC) cuticle with and without Sr loading. 


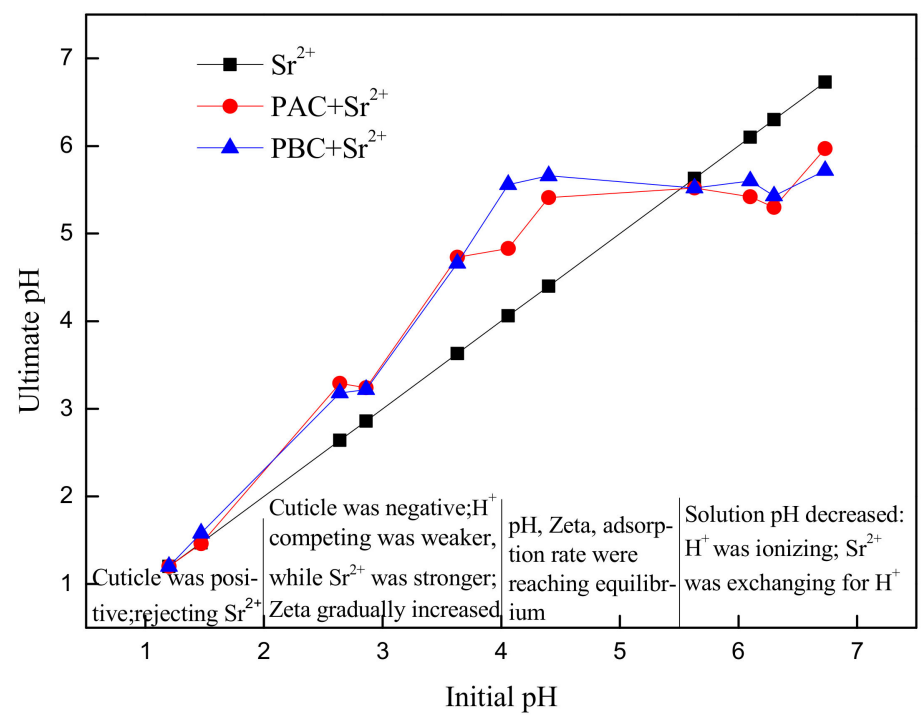

Figure 7. Solution $\mathrm{pH}$ before and after Sr adsorption by adaxial (PAC) and abaxial (PBC) cuticle of Photinia serrulata Leaf.

When $\mathrm{pH}$ value was lower than 2, the removal rate of Sr was nearly zero, and the zeta potential of both cuticles almost remained unchanged after being in contact with $\mathrm{Sr}$ [25]. This was attributed to the intensively protonation of functional group (such as $-\mathrm{OH},-\mathrm{NH}_{2}$ ) which made it difficult for $\mathrm{Sr}$ and cuticle particle to access each other. The $\mathrm{pH}$ value of working solution also remained unchanged suggesting no obvious adsorption of $\mathrm{H}^{+}$. With $\mathrm{pH}$ value further increasing, the adsorption rate was firstly drastically increased $(\mathrm{pH}, 2-4)$ and then gradually came to equilibrium $(\mathrm{pH} \geq 4)$. Corresponding, zeta potential increased slowly after Sr adsorbed. When $\mathrm{pH}$ value was between 3 and 4 , zeta potential began to drastically increase after Sr loading, and the removal rate also rose rapidly. When $\mathrm{pH}$ value was between 4 and 7, zeta potential gradually came to equilibrium after $\mathrm{Sr}$ adsorbed and the related adsorption rate reached its equilibrium, suggesting that adsorption behavior of cuticle was importantly affected by the surface charge of sorbents particles. The equilibrium value of zeta potential of adaxial cuticle $(-11.5 \mathrm{mV})$ was greater than the abaxial cuticle $(-13.0 \mathrm{mV})$, indicating a stronger binding with Sr of adaxial cuticle.

The correlation between the adsorption rate and the increase in zeta potential before and after Sr loading $(\Delta$ Zeta) is shown in Figure 8 . The positive correlation between the adsorption rate and increases in zeta potential was exhibited, indicating that the key mechanism of adsorption was electrostatic attraction and complex reaction rather ion exchange. The increase in zeta potential represented the growth of the surface charges of the adsorbent, and the ion exchange was an equal value exchange that would not change the amount of surface charges. Hence, the reason why the amount of (negative) charges was reduced after the adsorption was that part of the negative surface charges were counteracted by the electrostatic attraction and complex reaction with the cations.

The $\mathrm{pH}$ values of the abaxial and adaxial cuticles of Photinia fraseri before and after Sr were adsorbed are shown in Figure 7. When the $\mathrm{pH}$ value was less than 5.5, the $\mathrm{pH}$ of the solution increased after $\mathrm{Sr}$ were adsorbed, indicating that the negatively charged cuticles had adsorbed the $\mathrm{H}^{+}$in the solution. When $\mathrm{pH}$ value was greater than 5.5 , the $\mathrm{pH}$ of solution dropped. The decline in $\mathrm{pH}$ was not caused by the hydrolysis of $\mathrm{Sr}$, because the hydrolysis constant of $\mathrm{Sr} \log \beta_{1}=-13.29$ and $\log \beta_{2}=-28.51$, suggesting that when $\mathrm{pH}$ was between 1 and 7 , the $\operatorname{Sr}(\mathrm{OH})^{+}$and $\mathrm{H}^{+}$generated from hydrolysis could be ignored [26]. There were two aspects of the $\mathrm{pH}$ reducing effect: on the one hand, $\mathrm{H}^{+}$were separated by the $-\mathrm{OH}$ and $-\mathrm{COOH}$ acidic functional groups; on the other hand, the ion exchange occurred between $\mathrm{Sr}$ and $\mathrm{H}^{+}$, substituting $\mathrm{H}^{+}$. When the $\mathrm{pH}$ value was greater than $5.5\left(\mathrm{H}^{+} \leq 3,16 \times 10^{-6} \mathrm{~mol} \cdot \mathrm{L}^{-1}\right)$, the $\mathrm{pH}$ began to fall, indicating that the ion exchange was very weak, far less so than the physical electrostatic interaction. 


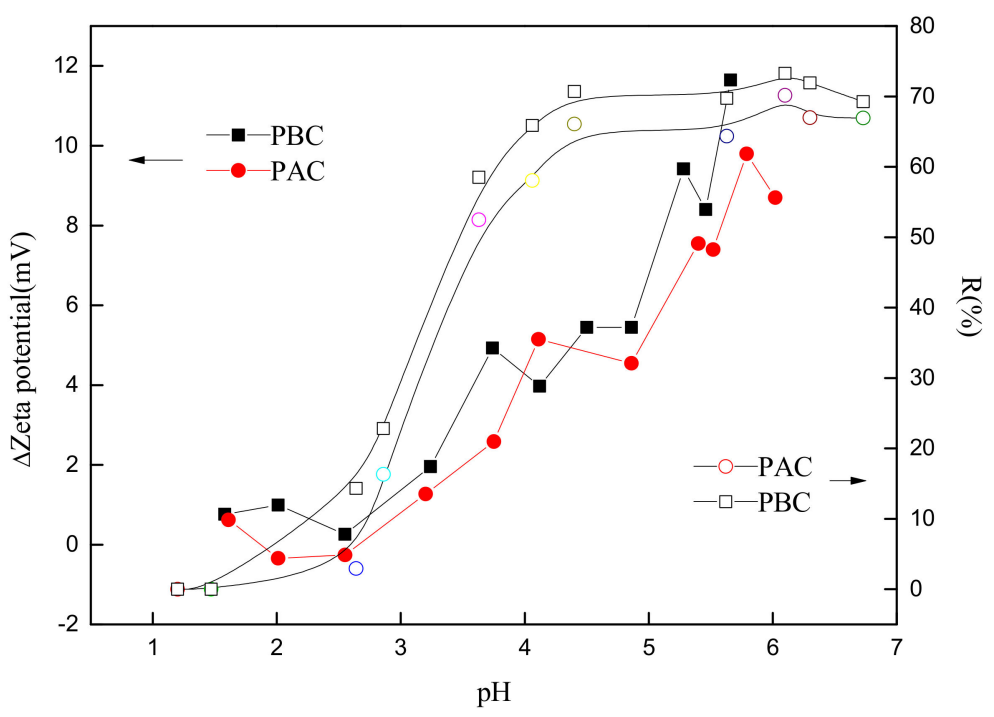

Figure 8. Relationship of removal rate and the change of zeta potential of cuticle before and after $\mathrm{Sr}$ adsorption by adaxial (PAC) and abaxial (PBC) cuticle of Photinia serrulata Leaf.

\subsection{FTIR Spectra of the Cuticles before and after Loading with Sr}

The infrared spectrum of the abaxial and adaxial foliar cuticles of Photinia fraseri is shown in Figure 9. The characteristic functional groups in the abaxial and adaxial foliar cuticles did not change importantly before and after the adsorption for $\mathrm{Sr}$, suggesting that there was no chemical precipitation in the adsorption of cuticles for Sr. For PAC, after Sr were adsorbed, the peaks at 2926, 2856, 1736, $1464,1421,1246,1164$, and $1062 \mathrm{~cm}^{-1}$ were intensified, showing that $\mathrm{C}-\mathrm{H},-\mathrm{COOH}$, and $\mathrm{C}-\mathrm{O}-\mathrm{C}$ were all involved in the adsorption; while the peak at $1629 \mathrm{~cm}^{-1}$ moved towards the low wave-number to $1626 \mathrm{~cm}^{-1}$, following $\mathrm{Sr}$ adsorption, the $\mathrm{H}^{+}$in carboxyl groups were replaced, causing a decline in the vibration intensity of the $\mathrm{C}=\mathrm{O}$ bond and a reduced wave number at the maximum adsorption peak. For PBC, the peak intensities almost remained unchanged, but the one at $1464 \mathrm{~cm}^{-1}$ moved towards the low wave-number by $4 \mathrm{~cm}^{-1}$, while those at 2927, 1629 , and $1062 \mathrm{~cm}^{-1}$ moved towards the low wave-number by $1-2 \mathrm{~cm}^{-1}$, showing that $\mathrm{C}-\mathrm{H}$, phenolic hydroxyl group, and $\mathrm{C}-\mathrm{O}-\mathrm{C}$ might have undergone ligand complexation and ion exchange with Sr.
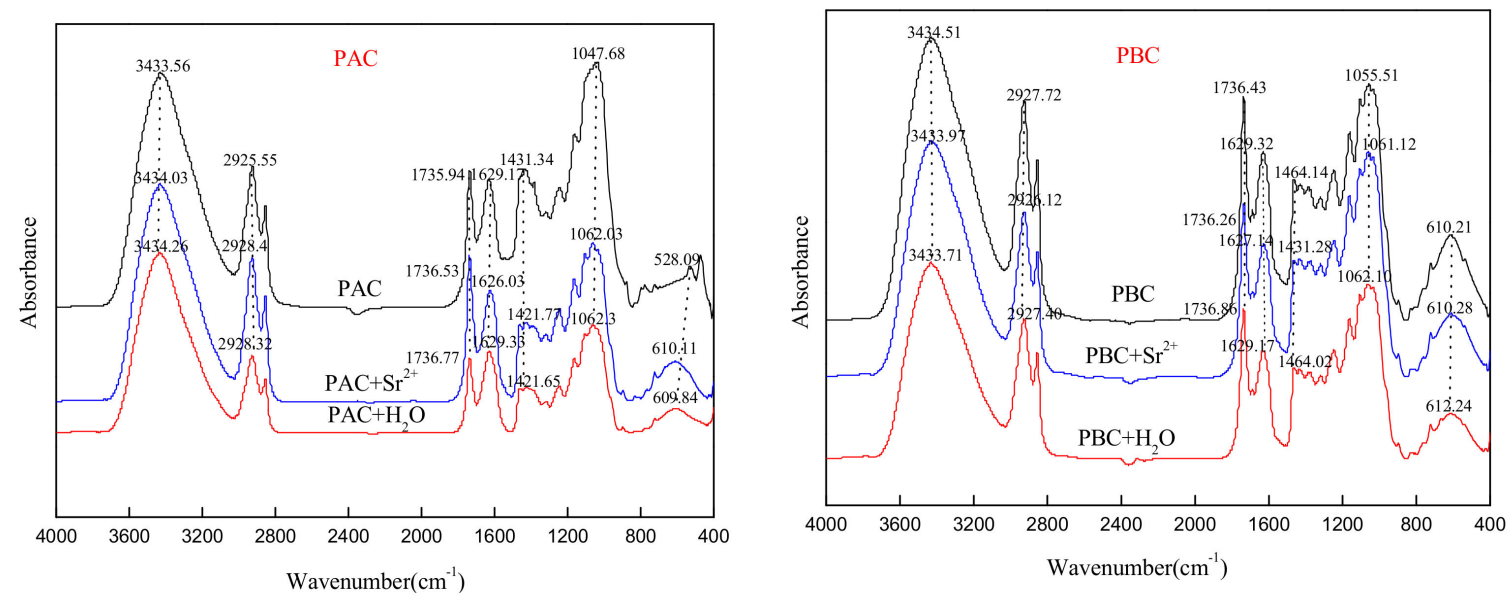

Figure 9. FTIR spectrometer of cuticle before and after Sr adsorption by adaxial (PAC) and abaxial (PBC) cuticle of Photinia serrulata Leaf. 


\section{Conclusions}

1. The elemental composition and FTIR spectra for both adaxial and abaxial cuticles were quite similar and both show high affinity $(\mathrm{H} / \mathrm{C}, 1.59$ and 1.65) and polarity $((\mathrm{O}+\mathrm{N}) / \mathrm{C}, 0.470$ and 0.499$)$. Adsorption of Sr onto adaxial and abaxial cuticles was up to equilibrium with $10 \mathrm{~min}$, and both adsorption isotherms fit well with Langmuir model $\left(R^{2}, 0.97\right.$ and 0.97$)$.

2. Neither adaxial nor abaxial cuticles play a negative role on the absorption of nuclide which was usually considered to be a barrier for the foliar uptake of pollutants, but showed a strong retention capacity for the nuclides in the environment. The maximum adsorption capacity of PAC was $12.1 \mathrm{mg} \cdot \mathrm{g}^{-1}$, little higher than that of PBC $\left(10.3 \mathrm{mg} \cdot \mathrm{g}^{-1}\right)$.

3. The adsorption of $\mathrm{Sr}$ increased with the increase of $\mathrm{pH}$, and the maximum was attained when $\mathrm{pH} \geq 4$. Electrostatic attraction was demonstrated to be the main mechanism of Sr adsorption onto PAC and PBC, and the similar adsorption of adaxial and abaxial cuticles was consistent with their similar isoelectric point $(\approx 2)$.

4. Importantly, the characteristic functional groups in the abaxial and adaxial foliar cuticles did not change before and after the adsorption for Sr, suggesting that there was no chemical precipitation in the adsorption of cuticles for Sr.

Author Contributions: Y.L. conceived and designed the experiments; X.L., X.B., W.L. and Y.L. performed the experiments and analyzed the data; Y.L. and X.L. wrote the paper; Y.L. and X.L. revised the paper. All authors have read and approved the final manuscript.

Funding: This research was funded by the International Cooperation Project of Sichuan provincial science and Technology Department (2017HH0042), the Young Scientists Fund of the National Natural Science Foundation of China (No. 21307100).

Acknowledgments: This work was supported by the National Natural Science Foundation of China (21307100), International cooperation project of Science and Technology Department in Sichuan province (2017HH0042).

Conflicts of Interest: The authors declare no conflict of interest.

\section{References}

1. Buesseler, K.; Aoyama, M.; Fukasawa, M. Impacts of the Fukushima nuclear power plants on marine radioactivity. Environ. Sci. Technol. 2011, 45, 9931-9935. [CrossRef] [PubMed]

2. Garnierlaplace, J.; Beaugelinseiller, K.; Hinton, T.G. Fukushima wildlife dose reconstruction signals ecological consequences. Environ. Sci. Technol. 2011, 45, 5077-5078. [CrossRef] [PubMed]

3. Kato, H.; Onda, Y.; Hisadome, K.; Loffredo, N.; Kawamori, A. Temporal changes in radiocesium deposition in various forest stands following the Fukushima Dai-ichi Nuclear Power Plant accident. J. Environ. Radioact. 2017, 166, 449-457. [CrossRef] [PubMed]

4. Parache, V.; Pourcelot, L.; Rousseldebet, S.; Orjollet, D.; Leblanc, F.; Soria, C.; Gurriaran, R.; Renaud, P.; Masson, O. Transfer of ${ }^{131}$ I from Fukushima to the vegetation and milk in France. Environ. Sci. Technol. 2011, 45, 9998-10003. [CrossRef] [PubMed]

5. Shozugawa, K.; Nogawa, N.; Matsuo, M. Deposition of fission and activation products after the Fukushima Dai-ichi nuclear power plant accident. Environ. Pollut. 2012, 163, 243-247. [CrossRef]

6. Kanasashi, T.; Sugiura, Y.; Takenaka, C.; Hijii, N.; Umemura, M. Radiocesium distribution in sugi (Cryptomeria japonica) in Eastern Japan: Translocation from needles to pollen. J. Environ. Radioact. 2015, 139, 398-406. [CrossRef]

7. Madoz-Escande, C.; Henner, P.; Bonhomme, T. Foliar contamination of Phaseolus vulgaris with aerosols of ${ }^{137} \mathrm{Cs},{ }^{85} \mathrm{Sr},{ }^{133} \mathrm{Ba}$ and ${ }^{123 \mathrm{~m}} \mathrm{Te}$ : Influence of plant development stage upon contamination and rain. J. Environ. Radioact. 2004, 73, 49-71. [CrossRef]

8. Chen, B.L.; Li, Y.G. Sorption of 1-naphthol by plant cuticular fractions. J. Environ. Sci. 2007, 19, 1214-1220. [CrossRef]

9. Li, Q.Q.; Chen, B.L. Organic pollutant clustered in the plant cuticular membranes: Visualizing the distribution of phenanthrene in leaf cuticle using two-photon confocal scanning laser microscopy. Environ. Sci. Technol. 2014, 48, 4774-4781. [CrossRef] 
10. Nishikiori, T.; Watanabe, M.; Koshikawa, M.K.; Takamatsu, T.; Ishii, Y.; Ito, S.; Takenaka, A.; Watanabe, K.; Hayashi, S. Uptake and translocation of radiocesium in cedar leaves following the Fukushima nuclear accident. Sci. Total Environ. 2015, 502, 611-615. [CrossRef]

11. Chefetz, B. Sorption of phenathrene and atrazine by plant cuticular fractions. Environ. Toxicol. Chem. 2003, 22, 2492-2498. [CrossRef] [PubMed]

12. Chen, B.L.; Li, Y.G.; Guo, Y.T.; Zhu, L.Z.; Schnoor, J.L. Role of the extractable lipids and polymeric lipids in sorption of organic contaminants onto plant cuticles. Environ. Sci. Technol. 2008, 42, 1517-1523. [CrossRef] [PubMed]

13. Li, Y.G.; Deng, Q.Q.; Chen, B.L. Sorption of chlorophenols onto fruit cuticles and potato periderm. J. Environ. Sci. 2012, 24, 675-681. [CrossRef]

14. Chen, B.L.; Johnson, E.J.; Chefetz, B.; Zhu, L.Z.; Xing, B.S. Sorption of polar and nonpolar aromatic organic contaminants by plant cuticular materials: role of polarity and accessibility. Environ. Sci. Technol. 2005, 39, 6138-6146. [CrossRef] [PubMed]

15. Li, Y.G.; Chen, B.L.; Zhu, L.Z. Single-solute and bi-solute sorption of phenanthrene and pyrene onto pine needle cuticular fractions. Environ. Pollut. 2010, 158, 2478-2484. [CrossRef] [PubMed]

16. Hunsche, M.; Noga, G. Cuticular wax load and surface wettability of leaves and fruits collected from sweet cherry (Prunus avium) trees grown under field conditions or inside a polytunnel. Acta Physiol. Plant. 2011, 33, 1785-1792. [CrossRef]

17. Mickle, J.E.; Lumaga, M.R.B.; Moretti, A.; Luca, P. Scanning electron microscopy studies of cuticle micromorphology in Cycas L. (Cycadaceae). Plant Biosyst. Int. J. Deal. All Asp. Plant Biol. 2011, 145, 191-201. [CrossRef]

18. Wild, E.; Dent, J.; Thomas, G.O.; Jones, K.C. Use of two-photon excitation microscopy and autofluorescence for visualizing the fate and behavior of semivolatile organic chemicals within living vegetation. Environ. Toxicol. Chem. 2008, 26, 2486-2493. [CrossRef]

19. Ahmadpour, A.; Zabihi, M.; Tahmasbi, M.; Bastami, T.R. Effect of adsorbents and chemical treatments on the removal of strontium from aqueous solutions. J. Hazard. Mater. 2010, 182, 552-556. [CrossRef]

20. Balarama Krishna, M.V.; Rao, S.V.; Arunachalam, J.; Murali, M.S.; Kumar, S.; Manchanda, V.K. Removal of ${ }^{137} \mathrm{Cs}$ and ${ }^{90} \mathrm{Sr}$ from actual low level radioactive waste solutions using moss as a phyto-sorbent. Sep. Purif. Technol. 2004, 38, 149-161. [CrossRef]

21. Chen, J.P. Batch and continuous adsorption of strontium by plant root tissues. Bioresour. Technol. 1997, 60, 185-189. [CrossRef]

22. Ai, L.; Luo, X.G.; Lin, X.Y.; Zhang, S.Z. Removal of Strontium ions from Aqueous Solution by Sunflower Straw. Adv. Mater. Res. 2013, 726, 1922-1925. [CrossRef]

23. Qian, L.B.; Chen, B.L. Dual role of biochars as adsorbents for aluminum: The effects of oxygen-containing organic components and the scattering of silicate particles. Environ. Sci. Technol. 2013, 47, 8759-8768. [CrossRef] [PubMed]

24. Yu, S.; Mei, H.; Chen, X.; Tan, X.L.; Ahmad, B.; Alsaedi, A.; Hayat, T.; Wang, X.K. Impact of environmental conditions on the sorption behavior of radionuclide $90 \mathrm{Sr}$ (II) on Na-montmorillonite. J. Mol. Liq. 2015, 203, 39-46. [CrossRef]

25. Gok, C.; Aytas, S. Biosorption of radiostrontium by alginate beads: Application of isotherm models and thermodynamic studies. J. Radioanal. Nucl. Chem. 2013, 295, 777-788. [CrossRef]

26. Cole, T.; Bidoglio, G.; Soupioni, M.; Gorman, M.O.; Gibson, N. Diffusion mechanisms of multiple strontium species in clay. Geochim. Cosmochim. Acta 2000, 64, 385-396. [CrossRef]

(C) 2020 by the authors. Licensee MDPI, Basel, Switzerland. This article is an open access article distributed under the terms and conditions of the Creative Commons Attribution (CC BY) license (http://creativecommons.org/licenses/by/4.0/). 